Article

\title{
Outcomes of Patients with Early Onset Colorectal Cancer Treated in a UK Specialist Cancer Center
}

\author{
Alexandros Georgiou ${ }^{1}$, Shelize Khakoo ${ }^{1}{ }^{1}$, Penelope Edwards ${ }^{1}$, Anna Minchom ${ }^{1}$, \\ Kyriakos Kouvelakis ${ }^{1}$, Eleftheria Kalaitzaki ${ }^{1}$, Natalie Nobar ${ }^{1}$, Vanessa Calamai ${ }^{1}$, Maria Ifijen ${ }^{1}$, \\ Olga Husson ${ }^{1,2} \mathbb{D}$, David Watkins ${ }^{1}$, Sheela Rao ${ }^{1}$, Ian Chau ${ }^{1} \mathbb{D}$, David Cunningham ${ }^{1}$ and \\ Naureen Starling ${ }^{1, * \mathbb{D}}$ \\ 1 Department of Medicine, The Royal Marsden Foundation Trust, London and Surrey SM2 5PT, UK; \\ a.georgiou@nhs.net (A.G.); shelize.khakoo@rmh.nhs.uk (S.K.); penelope.edwards@rmh.nhs.uk (P.E.); \\ anna.minchom@icr.ac.uk (A.M.); kyriakos_kouvelakis@yahoo.gr (K.K.); \\ eleftheria.kalaitzaki@rmh.nhs.uk (E.K.); natalie.nobar@gmail.com (N.N.); vanessacalamai@alice.it (V.C.); \\ maria.ifijen@rmh.nhs.uk (M.I.); olga.husson@icr.ac.uk (O.H.); david.watkins@rmh.nhs.uk (D.W.); \\ sheela.rao@rmh.nhs.uk (S.R.); ian.chau@rmh.nhs.uk (I.C.); david.cunningham@rmh.nhs.uk (D.C.) \\ 2 Department of Clinical Studies, Institute of Cancer Research, London SM2 5NG, UK \\ * Correspondence: naureen.starling@rmh.nhs.uk
}

Received: 20 September 2019; Accepted: 10 October 2019; Published: 14 October 2019

\begin{abstract}
The incidence of early onset colorectal cancer (EOCRC) is rapidly increasing, but there remains paucity of outcome data for young CRC patients. We reviewed the characteristics and outcomes of 241 adults, age $<50$, who were diagnosed with EOCRC between January 2009 and December 2014. Median age was 42,56\% were male, and 7\% had hereditary etiology. Seventy percent had left-sided primaries. At diagnosis, $11 \%, 50 \%$, and 39\% had stage II, III, and IV CRC. Of the patients with stage II and III CRC who underwent curative surgery, $60 \%$ and $88 \%$ had adjuvant chemotherapy, with 5 -year relapse free survival of $82 \%$ and $74 \%$ respectively. Of the 123 patients with metastatic (m) EOCRC, 93\%, 63\%, 33\%, and 12\% had 1st, 2nd, 3rd, and 4th line systemic anticancer therapy (SACT) respectively. For first line SACT, 99\% had doublet chemotherapy, with bevacizumab or an anti-EGFR antibody in 57\%. Median overall survival (mOS) of mEOCRC patients was 20.1 months (95\% C.I: 15.9-23.2). Younger age and signet cells were associated with shorter mOS, whereas more lines of SACT and curative metastasectomy with longer mOS. Metastatic EOCRC patients had poorer outcomes than expected, despite optimal multimodality treatment. This suggests an aggressive disease biology that warrants further research and therapy development.
\end{abstract}

Keywords: early onset; young adults; colorectal cancer; chemotherapy; treatment; outcomes

\section{Introduction}

Colorectal cancer (CRC) is the third most common cancer diagnosis worldwide [1]. It is traditionally considered a disease of older adults, therefore, in the United Kingdom (UK) fecal occult blood CRC screening is typically reserved for people over the age of 60. Similarly, CRC screening is limited to patients older than 50 years in the United States of America (USA) [2]. Early onset colorectal cancer (EOCRC) is defined as diagnosis of CRC in patients younger than 50 years old. Over recent years, there has been a significant increase in the incidence of EOCRC, with the highest rate of increase seen in rectal cancer. Epidemiological studies across the globe, including in Europe, Canada, USA, Australia, China, India, Japan, and Brazil, report a similar rise in incidence of CRC in young adults over the last 20-25 years [3-6]. In the USA, colon cancer incidence rates increased by $1.0 \%$ to $2.4 \%$ annually since the mid-1980s in adults age 20 to 39 years and by $0.5 \%$ to $1.3 \%$ since the mid-1990s in adults aged 
40 to 54 years. Rectal cancer incidence rates have been increasing for longer and more rapidly (3.2\% annually from 1974 to 2013 in adults aged 20-29 years) [7]. It is estimated that around $11 \%$ of colon cancers and $18 \%$ of rectal cancers occur in individuals younger than 50 years of age [8].

EOCRC appears to be a heterogeneous disease with distinct clinicopathological and molecular characteristics. Young adults tend to have a higher prevalence of low-grade tumor differentiation, mucinous and signet ring cell tumors when compared to older patients $[9,10]$. A proportion of EOCRC can be attributed to hereditary syndromes. It is estimated that up to $20-30 \%$ of EOCRC has a hereditary component. Of these, only 3-5\% have a well-characterized genetic basis [11]. The rate of EOCRC attributed to known hereditary syndromes is heavily influenced by the age groups analyzed, with patients $<35$ years old exhibiting the highest rates [12]. Lynch Syndrome (LS) is the most prevalent hereditary syndrome, followed by familial adenomatous polyposis (FAP), Peutz-Jeghers syndrome, juvenile polyposis syndrome, and others. The reported prevalence of LS in EOCRC cohorts is variable ranging from $4 \%$ to $20 \%$ [13]. The underlying pathogenesis of LS relates to the presence of germ-line mutations in one of the DNA mismatch repair (MMR) genes, which in itself results in microsatellite instability (MSI) [14]. In addition to MSI secondary to LS, MSI tumors can also be found in sporadic, nonhereditary cases. The majority of these cases occur secondary to epigenetic silencing of the MLH1 gene. Overall it is estimated that $15 \%$ to $20 \%$ of cases of EOCRC have MSI, a rate that is higher than that of older adults, albeit still a minority group [15].

The current literature relating to EOCRC is mainly limited to epidemiological studies that characterized the incidence and prognosis of younger adults with CRC. There is currently very sparse literature describing treatment pathways of these patients and their associated outcomes.

We aimed to profile the clinicopathological characteristics and treatment outcomes of patients with EOCRC (age $<50$ years) in the real-world setting of a single high-volume tertiary UK cancer center.

\section{Results}

\subsection{Patient Characteristics}

During the 6-year period of 1 January, 2009 to 31 December, 2014, a total of 561 patients aged 18-49 were registered at Royal Marsden Hospital (RMH) and had a diagnosis of CRC. Out of the 561 patients, 241 (43\%) patients met our inclusion criteria. The excluded patients had received their treatment in other UK centers or overseas and therefore their treatment outcomes were not available for extraction. The majority of excluded patients attended RMH for a single specialist review with the surgical, clinical, or medical oncology teams, including consultations to discuss participation in clinical trials.

The median age of all included patients was 42 years old (range 19 to 49 ) and $56 \%$ were male (Table 1). In total, 103 (43\%) patients were $<40$ years old. The majority of patients declared a white British (65\%) ethnicity followed by Asian or Asian British (10\%). The Body Mass Index (BMI) within 3 months of diagnosis was available for 227 (94\%) patients. The median BMI was $24.9 \mathrm{~kg} / \mathrm{m}^{2}(95 \%$ C.I 24.3-25.2), with a mean of $25.1 \mathrm{~kg} / \mathrm{m}^{2}$ (range 16.4-40.9). Overall, 231 (96\%) patients had an Eastern Cooperative Oncology Group (ECOG) performance status (PS) of 0 or one at diagnosis.

Twenty-seven (11\%) patients presented with stage II disease. Most patients presented with stage III disease $(n=120,(50 \%))$ and $93(39 \%)$ patients had metastatic disease at diagnosis.

Overall the majority of patients had a left sided primary tumor $(70 \%)$ with rectum/rectosigmoid being the most prevalent primary site $(n=102(43 \%))$ followed by descending or sigmoid colon $(n=64$ $(27 \%))$ and caecum/ascending colon $(n=57(24 \%))$.

There were 23 cases $(10 \%)$ of mucinous adenocarcinoma. Six ( $2 \%)$ patients had signet cells and out of these, five $(83 \%)$ had metastatic disease at diagnosis. Most primary tumors $(73 \%)$ were moderately differentiated, whereas $19 \%$ were poorly differentiated. 
Table 1. Baseline patient demographics and disease characteristics by stage at diagnosis. ECOG, Eastern Cooperative Oncology Group.

\begin{tabular}{|c|c|c|c|c|}
\hline Variable & $\begin{array}{c}\text { Stage II } \\
n(\%)\end{array}$ & $\begin{array}{c}\text { Stage III } \\
n(\%)\end{array}$ & $\begin{array}{c}\text { Stage IV } \\
n(\%)\end{array}$ & $\begin{array}{c}\text { All Patients } \\
n(\%)\end{array}$ \\
\hline Stage at diagnosis * & $27(11)$ & $120(50)$ & $93(39)$ & $241(100)$ \\
\hline \multicolumn{5}{|l|}{ Sex } \\
\hline Female & $13(48)$ & 47 (39) & $46(49)$ & $107(44)$ \\
\hline Male & $14(52)$ & $73(61)$ & $47(51)$ & $134(56)$ \\
\hline \multicolumn{5}{|l|}{ Age } \\
\hline Mean & 40 & 40 & 41 & 40 \\
\hline Median & 40 & 43 & 43 & 42 \\
\hline Range (min-max) & $25-49$ & $25-49$ & $21-49$ & $19-49$ \\
\hline$<20$ & $0(0)$ & $1(<1)$ & $0(0)$ & $1(<1)$ \\
\hline $20-29$ & $2(7)$ & $12(10)$ & $10(11)$ & $24(10)$ \\
\hline 30-39 & $11(41)$ & $39(33)$ & $28(30)$ & $78(32)$ \\
\hline $40-49$ & $14(52)$ & $68(57)$ & $55(59)$ & $138(57)$ \\
\hline \multicolumn{5}{|l|}{ Ethnic Background } \\
\hline White British & $14(52)$ & $77(64)$ & $64(69)$ & $156(65)$ \\
\hline White Irish & $0(0)$ & $3(2)$ & $1(1)$ & $4(2)$ \\
\hline White Other & $2(7)$ & $8(7)$ & $8(9)$ & $18(7)$ \\
\hline Asian/Asian-British & $2(7)$ & $14(12)$ & $8(9)$ & $24(10)$ \\
\hline African/Caribbean/Black British & $4(15)$ & $10(8)$ & $4(4)$ & $18(7)$ \\
\hline Mixed/Multiple (Other Mixed) & $1(4)$ & $0(0)$ & $0(0)$ & $1(<1)$ \\
\hline Another Ethnic Group & $4(15)$ & $8(7)$ & $8(9)$ & $20(8)$ \\
\hline \multicolumn{5}{|l|}{ ECOG PS } \\
\hline 0 & $12(44)$ & $24(20)$ & $16(17)$ & $52(22)$ \\
\hline 1 & $15(56)$ & $95(79)$ & $68(73)$ & $179(74)$ \\
\hline 2 & $0(0)$ & $1(1)$ & $4(4)$ & $5(2)$ \\
\hline 3 & $0(0)$ & $0(0)$ & $5(5)$ & $5(2)$ \\
\hline \multicolumn{5}{|l|}{ Location of primary tumor } \\
\hline Caecum/ascending colon & $5(18)$ & $31(26)$ & $21(23)$ & $57(24)$ \\
\hline Transverse colon & $3(11)$ & $10(8)$ & $5(5)$ & $18(7)$ \\
\hline Descending colon/sigmoid & $7(26)$ & $26(22)$ & $31(33)$ & $64(26)$ \\
\hline Recto-sigmoid & $1(4)$ & $4(3)$ & $11(12)$ & $16(7)$ \\
\hline Rectum & $11(41)$ & $49(41)$ & $25(27)$ & $86(36)$ \\
\hline \multicolumn{5}{|l|}{ Histology } \\
\hline Adenocarcinoma & $23(85)$ & $103(86)$ & $83(89)$ & $210(87)$ \\
\hline Mucinous adenocarcinoma & $4(15)$ & $16(13)$ & $3(3)$ & $23(10)$ \\
\hline Signet cell & $0(0)$ & $1(1)$ & $5(5)$ & $6(2)$ \\
\hline Unknown & $0(0)$ & $0(0)$ & $2(2)$ & $2(1)$ \\
\hline \multicolumn{5}{|l|}{ Primary Tumor differentiation } \\
\hline Well & $1(4)$ & $3(2)$ & $0(0)$ & $4(2)$ \\
\hline Moderate & $23(85)$ & $93(78)$ & $60(65)$ & $176(73)$ \\
\hline Poor & $3(11)$ & $21(18)$ & $20(21)$ & $45(19)$ \\
\hline Unknown & $0(0)$ & $3(2)$ & $13(14)$ & $16(6)$ \\
\hline \multicolumn{5}{|l|}{ KRAS } \\
\hline Mutant & $8(30)$ & $18(15)$ & $23(25)$ & $49(20)$ \\
\hline Wild type & $4(15)$ & $35(29)$ & $46(50)$ & $85(35)$ \\
\hline Unknown & $15(55)$ & $67(56)$ & $24(26)$ & $107(44)$ \\
\hline \multicolumn{5}{|l|}{ NRAS } \\
\hline Mutant & 0 & 0 & 0 & 0 \\
\hline Wild type & $6(22)$ & $31(26)$ & $28(30)$ & $65(27)$ \\
\hline Unknown & $21(78)$ & $89(74)$ & $65(70)$ & $176(73)$ \\
\hline
\end{tabular}


Table 1. Cont.

\begin{tabular}{lllll}
\hline Variable & \multicolumn{1}{c}{$\begin{array}{c}\text { Stage II } \\
\boldsymbol{n} \mathbf{( \% )}\end{array}$} & $\begin{array}{c}\text { Stage III } \\
\boldsymbol{n} \mathbf{( \% )}\end{array}$ & $\begin{array}{c}\text { Stage IV } \\
\boldsymbol{n} \mathbf{( \% )}\end{array}$ & $\begin{array}{c}\text { All Patients } \\
\boldsymbol{n} \mathbf{( \% )}\end{array}$ \\
\hline $\begin{array}{l}\text { BRAF } \\
\text { Mutant }\end{array}$ & $0(0)$ & $8(7)$ & $4(4)$ & $12(5)$ \\
$\quad$ Wild type & $6(22)$ & $24(20)$ & $24(26)$ & $54(22)$ \\
$\quad$ Unknown & $21(78)$ & $88(73)$ & $65(70)$ & $175(73)$ \\
\hline MMR & $3(11)$ & $13(11)$ & $1(1)$ & $17(7)$ \\
$\quad$ Deficient & $22(82)$ & $69(57)$ & $56(60)$ & $148(61)$ \\
$\quad$ Proficient & $2(7)$ & $38(32)$ & $36(39)$ & $76(32)$ \\
$\quad$ Unknown & & & \\
\hline Hereditary Syndromes & $3(11)$ & $7(6)$ & $1(1)$ & $11(5)$ \\
$\quad$ Lynch syndrome & $1(4)$ & $0(0)$ & $0(0)$ & $1(<1)$ \\
$\quad$ FAP & $0(0)$ & $3(3)$ & $1(1)$ & $4(2)$ \\
$\quad$ Other & & & \\
\hline
\end{tabular}

* 1 patient had stage I rectal cancer at diagnosis.

MMR status, assessed by immunohistochemistry, was available in $165(68 \%)$ patients, and of these, 148 (90\%) had MMR proficient tumors. In patients with known MMR status with stage II disease at diagnosis, $12 \%$ had MMR deficient tumors. In patients with stage III disease the rate of MMR deficiency was $16 \%$, whereas in patients with stage IV disease at diagnosis, only one ( $2 \%)$ patient had MMR deficient CRC. Out of the 17 patients that were known to have MMR deficient tumors, 11 (65\%) patients were known to have Lynch syndrome.

A total of sixteen patients (7\%) with EOCRC were found to have a known hereditary syndrome. As expected, the most prevalent hereditary syndrome was Lynch syndrome $(n=11)$.

Routine molecular characterization of patients' tumors with stage IV disease evolved during the course of the 6-year period included (January 2009-December 2014). In 2009, molecular characterization was not part of patients' routine care. Subsequently, KRAS mutation testing was carried out and by 2014, exon 2-4 NRAS/KRAS and BRAF mutation testing was considered standard of care. As a result of this, the majority of the included patients have an unknown NRAS and BRAF genetic mutation status. Out of the 134 patients with known KRAS status, 37\% had a known activating mutation.

\subsection{Treatment and Outcomes in Patients with Stage II and III EOCRC}

\subsubsection{Neo-Adjuvant Chemoradiation}

A total of $48(80 \%)$ patients with stage II or III rectal cancer were treated with neo-adjuvant radiotherapy and out of these patients, $44(92 \%)$ received long course chemo-radiation with concomitant capecitabine or 5FU. On pretreatment MRI imaging, a total of $23(48 \%)$ patients had documented circumferential resection margin involvement (CRM) and $32(67 \%)$ patients had evidence of extramural vascular invasion (EMVI). A total of four $(8 \%)$ patients had evidence of local or systemic relapse after completion of radiotherapy $(+/-$ chemotherapy).

\subsubsection{Curative Surgery and Adjuvant Chemotherapy}

A total of 15 (60\%) out of 25 patients with stage II disease that had a documented history of curative surgery went on to have adjuvant chemotherapy. Of these patients $80 \%$ had adjuvant capecitabine or 5FU alone. The 5-year relapse-free survival (RFS) for stage II patients was $82.2 \%$ (Figure 1). 


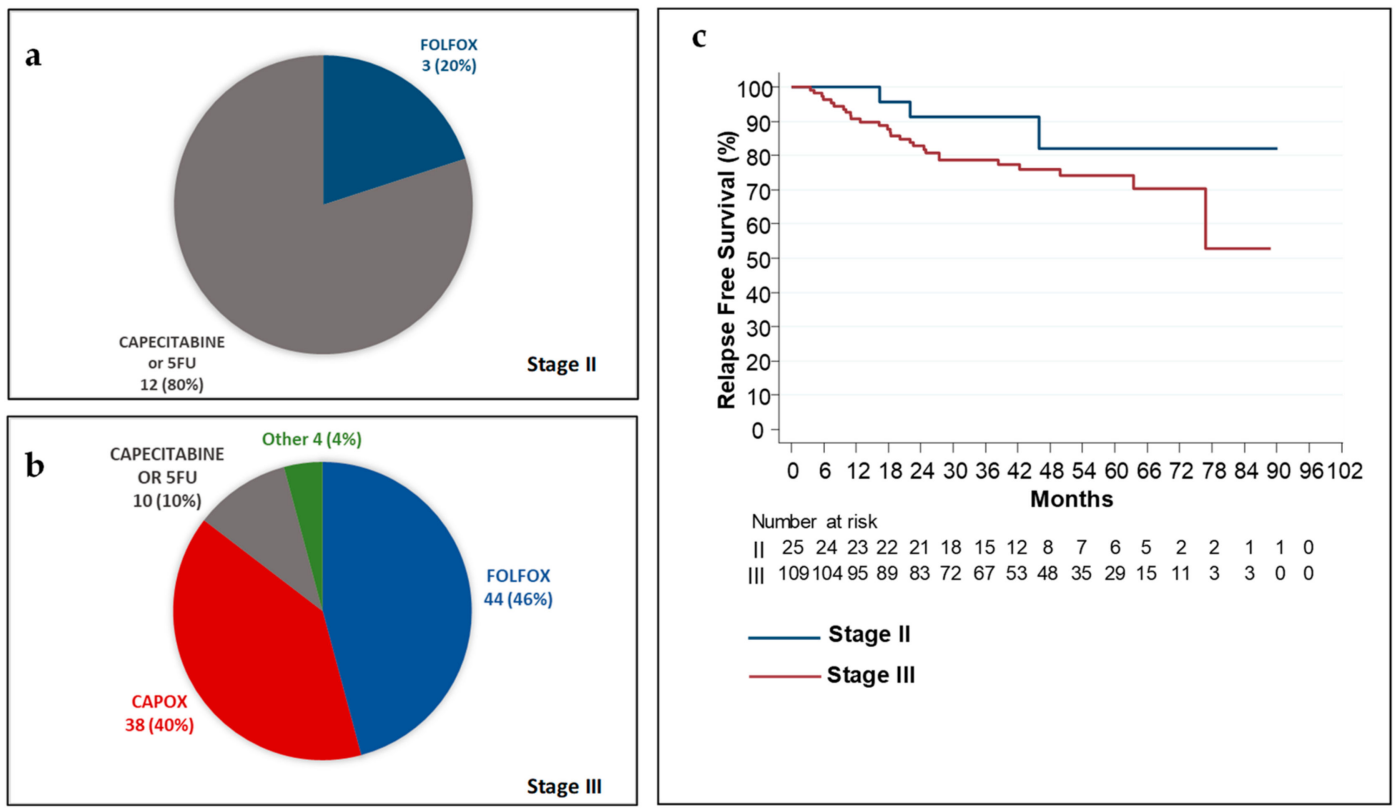

Figure 1. Adjuvant chemotherapy and Relapse Free Survival in patients with stage II and II colorectal cancer (CRC). (a) Adjuvant chemotherapy regimens in 15 patients with stage II CRC; (b) Adjuvant chemotherapy regimens in 96 patients with stage III CRC; (c) Kaplan-Meier estimates for relapse-free survival (RFS) in all patients with Stage II and III disease. 5FU: 12 cycles, each 14-day cycle; 5FU bolus $400 \mathrm{mg} / \mathrm{m}^{2}, 5 \mathrm{FU} 2400 \mathrm{mg} / \mathrm{m}^{2}$ infusion over $48 \mathrm{~h}$ and folinic acid $350 \mathrm{mg}$. Capecitabine 8 cycles each 21-day cycle; capecitabine $2000 \mathrm{mg} / \mathrm{m}^{2}$ per day in two divided doses for 14 days followed by 7-day rest. CAPOX: 8 cycles, each 21-day cycle; capecitabine $1700 \mathrm{mg} / \mathrm{m}^{2}$ per day in two divided doses for 14 days followed by 7-day rest and oxaliplatin $130 \mathrm{mg} / \mathrm{m}^{2}$ on day 1 . FOLFOX: 12 cycles, each 14-day cycle; $5 F U$ bolus $400 \mathrm{mg} / \mathrm{m}^{2}$, 5FU $2400 \mathrm{mg} / \mathrm{m}^{2}$ infusion over 48, folinic acid $350 \mathrm{mg}$ and oxaliplatin $85 \mathrm{mg} / \mathrm{m}^{2}$ on day 1 . Other: experimental combinations that were administered only within clinical trials: experimental regimens were FOLFOX or CAPOX with targeted therapies.

Out of the 109 patients with stage III disease that had curative surgery, $96(88 \%)$ patients were treated with adjuvant chemotherapy. Out of the patients that received adjuvant chemotherapy, $86 \%$ patients had standard of care oxaliplatin-based doublet chemotherapy, while four patients had oxaliplatin-based doublet in combination with targeted therapies within clinical trials. The 5-year relapse-free survival (RFS) for stage III patients was $74.1 \%$ (Figure 1).

Out of all the patients that were treated with adjuvant chemotherapy, $13(12 \%)$ patients had discontinuation of their adjuvant chemotherapy earlier than planned, while $30 \%$ required a treatment delay during the 6-month course of their adjuvant chemotherapy. Moreover, in 34 of the $88(39 \%)$ patients that were treated with oxaliplatin-based doublet chemotherapy, oxaliplatin was discontinued early, during their 6-month course of treatment.

\subsection{Treatment and Outcomes in Patients with Stage IV EOCRC}

A total of 123 patients with mEOCRC were included. Out of these, 93 (76\%) patients had stage IV disease at diagnosis, while two $(2 \%)$ patients had stage II and $28(23 \%)$ had stage III disease at diagnosis and relapsed with metastatic disease subsequently. A total of $114(93 \%)$ patients were treated with SACT for mEOCRC, while the rest of the patients were either of a poor PS at diagnosis and did not receive SACT or had oligometastatic disease and were treated with metastasectomy alone.

The most commonly administered regimens per line of SACT are shown in Figure 2. In the first line metastatic setting, out of the 114 patients that received SACT, $113(99 \%)$ patients received a doublet chemotherapy regimen, with the addition of bevacizumab in $48 \%$ of patients. 
a $1^{\text {st }}$ Line $\mathrm{n}=114(10 \%$ clinical trial $)$

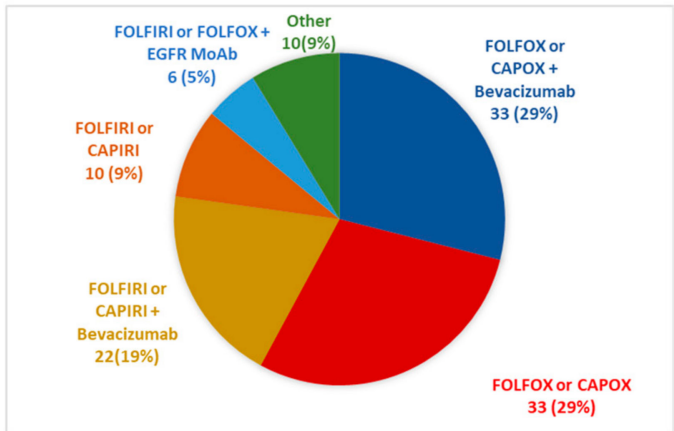

C $3^{\text {rd }}$ Line $\mathrm{n}=40(20 \%$ clinical trial $)$

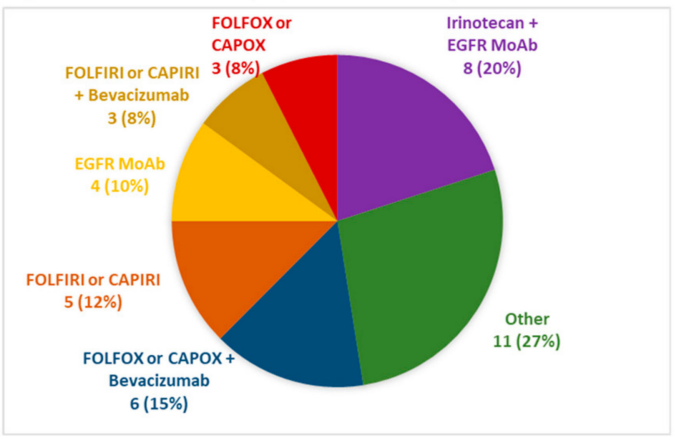

b $\quad 2^{\text {nd }}$ Line $\mathbf{n}=78(9 \%$ clinical trial $)$

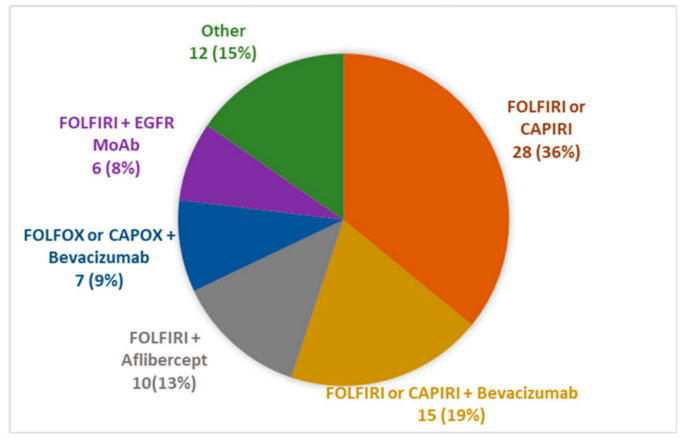

d $4^{\text {th }}$ Line $\mathrm{n}=15(20 \%$ clinical trial $)$

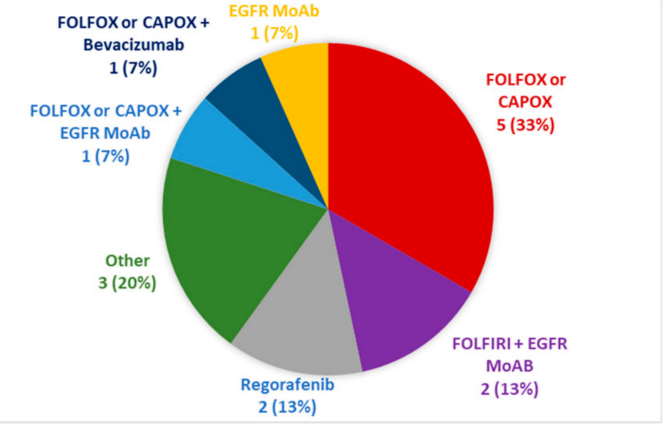

Figure 2. The most frequently used systemic anticancer therapy (SACT) regimens in the metastatic setting in (a) first line, (b) second line, (c) third line, and (d) fourth line setting. Epidermal Growth Factor Receptor (EGFR) Monoclonal antibody (MoAb) therapy (cetuximab $500 \mathrm{mg} / \mathrm{m}^{2}$ 2-weekly or panitumumab $6 \mathrm{mg} / \mathrm{kg}$ 2-weekly) was only offered in patients with known KRAS wild type tumors. FOLFIRI (14 day cycle: 5FU bolus $400 \mathrm{mg} / \mathrm{m}^{2}$ and 5FU $2400 \mathrm{mg} / \mathrm{m}^{2}$ infusion over $48 \mathrm{~h}$, folinic acid $350 \mathrm{mg}$ and irinotecan $180 \mathrm{mg} / \mathrm{m}^{2}$ day 1), CAPIRI (21 day cycle: capecitabine $1700 \mathrm{mg} / \mathrm{m}^{2}$ per day in two divided doses for 14 days followed by 7 day rest and irinotecan $200 \mathrm{mg} / \mathrm{m}^{2}$ on day 1), FOLFOX (14 day cycle: $5 F U$ bolus $400 \mathrm{mg} / \mathrm{m}^{2}, 5 \mathrm{FU} 2400 \mathrm{mg} / \mathrm{m}^{2}$ infusion over $48 \mathrm{~h}$ folinic acid $350 \mathrm{mg}$ and oxaliplatin $85 \mathrm{mg} / \mathrm{m}^{2}$ on day 1), CAPOX (21 day cycle: capecitabine $1700 \mathrm{mg} / \mathrm{m}^{2}$ per day in two divided doses for 14 days followed by 7 day rest and oxaliplatin $130 \mathrm{mg} / \mathrm{m}^{2}$ on day 1). Bevacizumab in all 3-weekly regimens at $7.5 \mathrm{mg} / \mathrm{kg}, 2$ weekly regimens at $5 \mathrm{mg} / \mathrm{kg}$. Aflibercept at $4 \mathrm{mg} / \mathrm{kg} 2$ weekly. Regorafenib 4 weekly cycles at $160 \mathrm{mg}$ once a day (OD) for 21 days followed by 7-day rest.

The documented partial response (PR) stable disease (SD) and progressive disease (PD) rates in the first line setting regardless of regimen were $40 \%, 23 \%$, and $32 \%$ respectively. The median PFS in the first line setting, was 6.9 (95\% C.I: 5.8-9.4) months (Table 2).

Of the patients that had first line SACT, $78(68 \%)$ went on to have a 2 nd line SACT. The most commonly used regimen in the second line setting was irinotecan-based combination with or without the addition of bevacizumab (36\% and 19\% respectively). The documented PR, SD, and PD rates were $17 \%, 26 \%$, and 51\% respectively. The median progression-free survival (PFS), irrespective of regimen, in the second line setting was 5.0 (95\% C.I: 3.4-6.1) months (Table 2).

A total of $33 \%, 12 \%$, and $5 \%$ of all patients with mEOCRC went on to receive $3 \mathrm{rd}, 4$ th, and 5 th line treatments respectively. The most commonly utilized SACT regimens in the 3rd and 4th line setting are shown in Figure 2 and outcomes per line of therapy in Table 2. As the number of lines of SACT increased, so did the participation of treatment within a clinical trial setting, with $20 \%$ of patients treated within clinical trials from the third line setting onwards.

The median overall survival (mOS) increased with increasing number of sequential lines of SACT (Table 2). Patients that were only able to receive a total of one line of SACT had a mOS of 9.0 (95\% C.I: 4.1-27.7) months. Patients that received a total of two lines had a mOS of 14.9 (95\% C.I: 9.6-19.0) 
months, while those that had a total of three and four lines of SACT had a mOS of 18.7 (95\% C.I: 14.3-28.6) and 31.7 (95\% C.I: 20.2-46.5) months respectively.

Table 2. Patient outcomes by total number of SACT received in the metastatic setting.

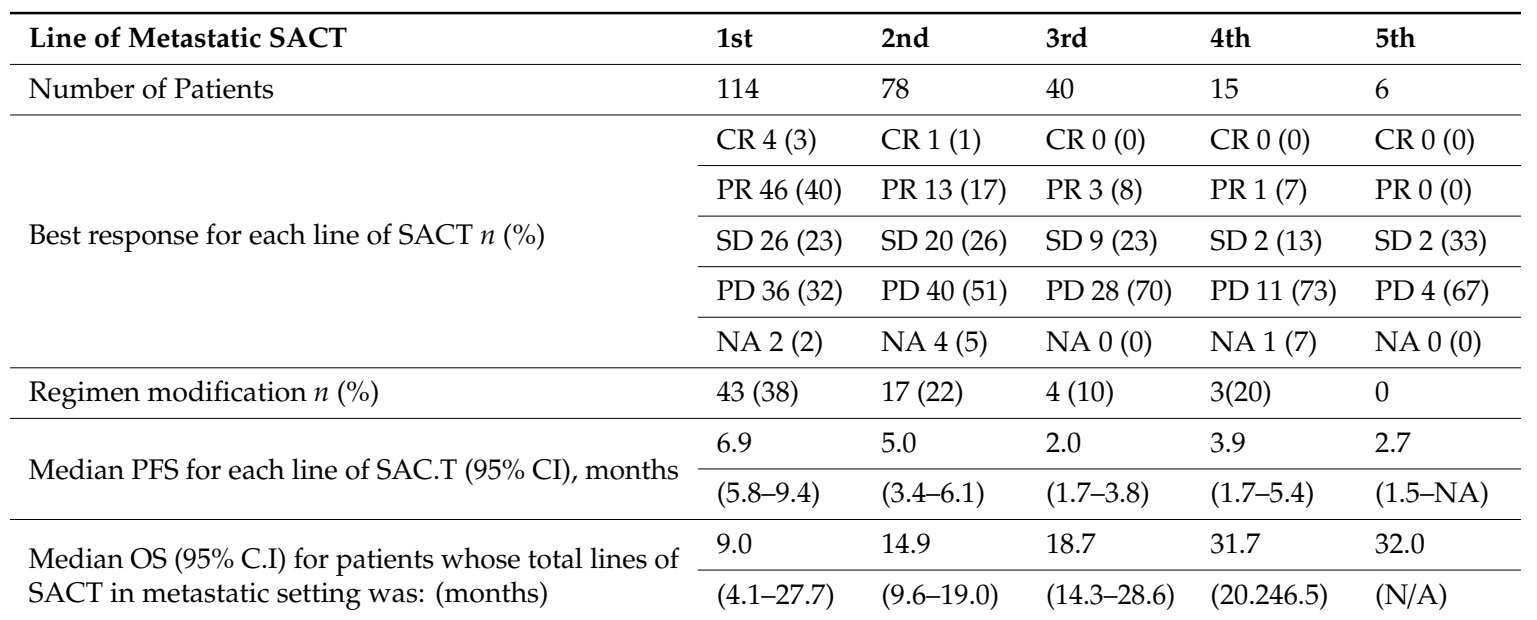

Legend: SACT: systemic anticancer therapy, CR: complete response, PR: partial response, SD: stable disease, PD: progressive disease, NA: not applicable. PFS: progression-free survival, OS: overall survival.

A total of 17 (14\%) patients underwent metastasectomy with curative intent. In addition, patients with metastatic disease received the following palliative treatments during the course of their treatment: $27(22 \%)$ patients had palliative radiotherapy, 21 (17\%) patients had palliative surgery to the primary tumor, 11 (9\%) patients had radiofrequency ablation (RFA) to the liver and or lung metastases, four (3\%) patients had stereotactic radiosurgery, four (3\%) patients had selective internal radiation therapy (SIRT) to liver metastasis, and two (2\%) patients had microwave ablation to the liver.

The mOS for all patients with mEOCRC was 20.1 months (95\% C.I: 15.9-23.2). For the 93 patients that presented with stage IV disease $(n=93)$, mOS was 18.8 months (95\% C.I: $14.3-22.6)$. In the case of patients that relapsed with systemic metastases following an initial diagnosis of stage II $(n=2)$ and III $(n=28)$ disease, the mOS from the time of diagnosis of metastatic disease was 9.1 (95\% C.I N/A) months and 26.2 (95\% C.I: 15.7-49.6) months respectively.

\subsection{Prognostic Markers of Survival in Patients with Stage IV CRC}

As expected, the $17(14 \%)$ patients that had curative metastasectomy had a statistically significant longer mOS ( $p<0.001)$, when compared to patients that did not (Figure 3$)$. In addition, $11(9 \%)$ patients that had metastatic disease that was deemed treatable with local ablative therapy to the liver and/or lung metastases also had significantly longer mOS (Figure 3). The latter analysis may have been confounded by the fact that these patients were likely to have had oligo-metastatic disease.

Patients with signet cells (5\%) had a significantly shorter mOS, although this analysis was limited by the small number of patients with signet cell histology (Table 3).

Younger age at presentation was associated with a numerically shorter mOS. As shown in Figure 3c, patients age $\leq 40$ had mOS of 16.1 (95\% C.I 9.9-28.6) compared to 21.7 months in patients age $>40$ group (95\% C.I 16.2-27.7).

When considering age groups per decade cohorts there was an inverse relationship between age and $\mathrm{mOS}$, with youngest patients having numerically the shortest $\mathrm{mOS}(p<0.05)$ :

- $\quad$ age 20-29 $(n=13), \operatorname{mOS} 15.9(95 \%$ C.I 7.0-43.0)

- $\quad$ age 30-39 $(n=37), \operatorname{mOS} 17.1(95 \%$ C.I not reached)

- $\quad$ age $40-49(n=72), \operatorname{mOS} 21.7$ (95\% C.I 16.2-27.7) 
The location of primary tumor (left vs. right sided) and KRAS and BRAF mutation status did not significantly impact on mOS (Table 3). The BRAF analysis was limited by the small number of patients that had known $B R A F$ genotyping results, although, as expected, patients with $B R A F$ wild type tumors had a numerically longer mOS when compared to patients with BRAF mutant tumors (Table 3).

\section{Discussion}

It is now recognized that the incidence of EOCRC is increasing rapidly at a global scale [3-6]. In the USA it is predicted that based on current trends, in 2030, the incidence rates for colon and rectal cancers will increase by $90.0 \%$ and $124.2 \%$, respectively, for patients aged 20 to 34 years and by $27.7 \%$ and $46.0 \%$, respectively, for patients aged 35 to 49 years [16].

In our study, a total of 561 patients, age $<50$, with EOCRC were registered over the 6-year period from January 2009 to December 2014. The sheer number of patients with EOCRC that were registered at a single cancer center, further highlights that patients with EOCRC represent a sizeable group, who merit further consideration in terms of bespoke therapy development and configuration of services.
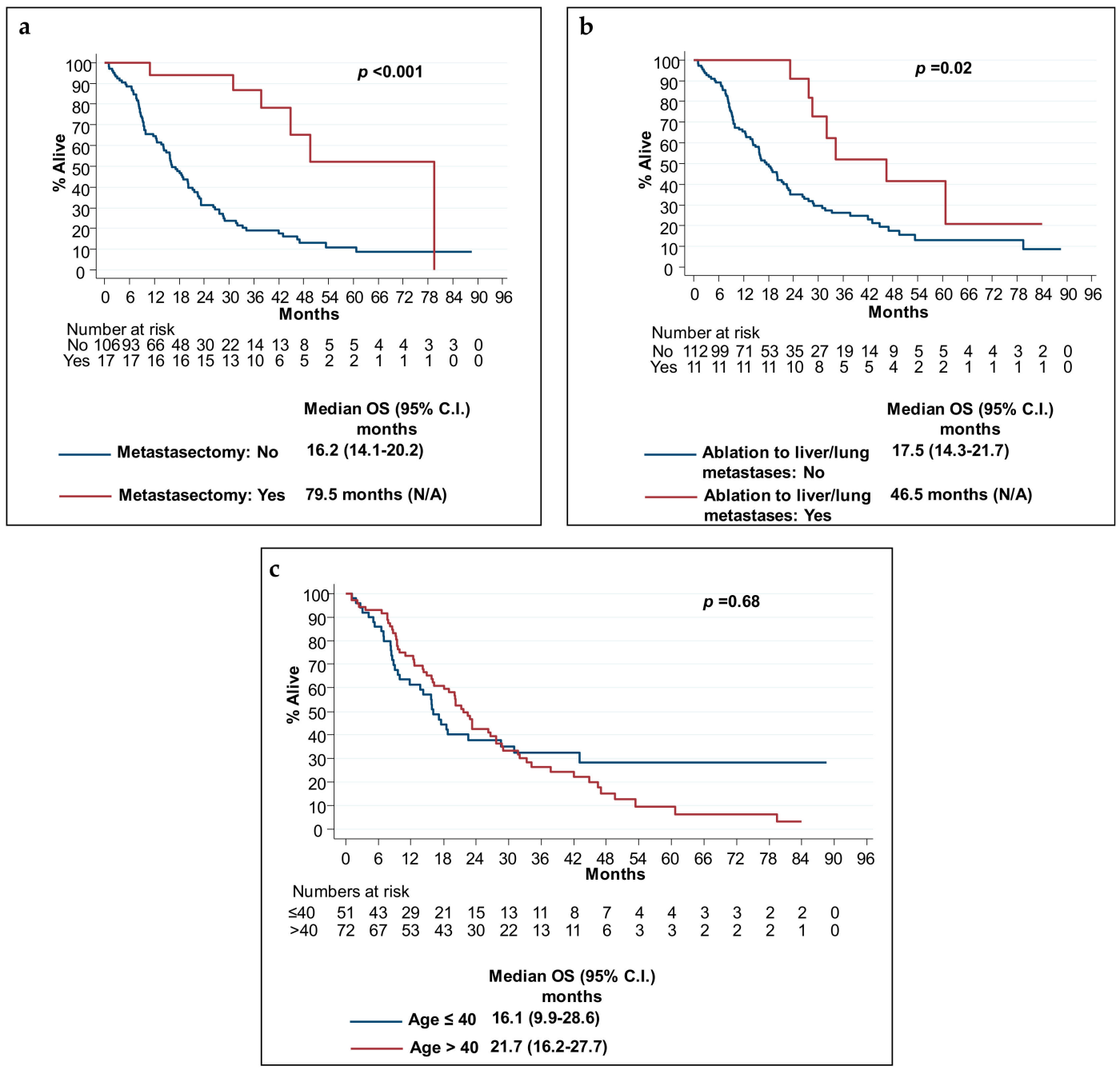

Figure 3. Prognostic markers for overall survival in metastatic disease. Kaplan-Meier estimates of overall survival according to (a) whether patients underwent metastasectomy with curative intent, (b) whether they had radiofrequency ablation to liver and/or lung metastases, and (c) age at diagnosis, $\leq 40$ years old or $>40$ years old. $p$-values refer to log rank test. 
Table 3. Prognostic variables for overall survival in the metastatic setting. mOS, Median overall survival.

\begin{tabular}{|c|c|c|c|}
\hline Prognostic Variable & $\begin{array}{l}\text { Number of } \\
\text { Patients }\end{array}$ & $\begin{array}{c}\text { mOS } \\
\text { (95\% C.I) } \\
\text { Months }\end{array}$ & $p$-Value \\
\hline \multicolumn{4}{|l|}{ Histopathology } \\
\hline Adenocarcinoma & 107 & $20.2(16.1-26.7)$ & \multirow{4}{*}{$p<0.001$} \\
\hline Mucinous & & & \\
\hline Adenocarcinoma & 7 & 15.8 (NA) & \\
\hline Signet cells & 5 & 7.0 (NA) & \\
\hline \multicolumn{4}{|l|}{ Location of Primary } \\
\hline Left & 90 & 22.5 (16.2-27.7) & \multirow{2}{*}{$p=0.18$} \\
\hline Right & 33 & $15.9(9.0-22.0)$ & \\
\hline \multicolumn{4}{|l|}{ KRAS Status * } \\
\hline Mutant & 32 & 18.5 (11.7-26.2) & \multirow{2}{*}{$p=0.38$} \\
\hline Wild Type & 56 & $22.6(17.1-28.8)$ & \\
\hline \multicolumn{4}{|l|}{$B R A F$ Status ** } \\
\hline Mutant & 7 & 17.1 (NA) & \multirow{2}{*}{$p=0.45$} \\
\hline Wild Type & 34 & $23.2(16.0-46.5)$ & \\
\hline
\end{tabular}

Legend: $p$-value refers to log rank test; * In 35 patient KRAS status was unknown; ** In 82 patients $B R A F$ status was unknown.

Out of the of $241(43 \%)$ patients that met our inclusion criteria, $56 \%$ were male and the majority (65\%) declared a White British ethnic background, followed by 10\% that declared Asian/Asian-British background. Overall, the ethnic background data of our population, while reflective of the multi-cultural London population, also suggest that in the UK, EOCRC is likely to span all ethnic backgrounds. Studies to date sought to identify population subgroups with the highest predisposition to EOCRC. While there have been some discrepancies between the outcomes reported in different countries, overall, the increase in incidence rates of EOCRC appears similar between males and females [5]. In the USA, there is data to suggest that there are persistent disparities by race/ethnicity and possibly socio-economic status. However, these disparities may reflect the relative distribution of other risk factors that are known to be associated with CRC, such as obesity and type II diabetes in these subgroups [17-19]. Our cohort had a median BMI that was within the normal distribution, median of $24.9 \mathrm{~kg} / \mathrm{m}^{2}$, albeit at the uppermost limit of normality.

In our population there was a left sidedness preponderance with $43 \%$ of patients having rectal or recto-sigmoid tumors as their primary site. Only $21 \%$ of patients presented with stage I or II disease, while $39 \%$ of patients had metastatic disease at diagnosis. Overall, our findings are in line with other studies that suggest that the incidence of rectal cancer is increasing most rapidly in young adults and that these patients tend to be diagnosed with advanced disease stage [19-22]. It is however worth noting that other epidemiological data from Europe suggests that the largest increase in CRC incidence in young adults is in fact of colon rather than rectal origin [3,23], thereby, challenging recent suggestions of screening strategies in young adults with flexible sigmoidoscopy alone [24].

Although we have not been able to investigate the prior diagnostic pathway of our patients, it has been previously suggested that young patients with CRC report symptoms for a longer period of time, prior to diagnosis, than their older counterparts $[25,26]$. It is possible that young CRC patients present with symptoms, such as bleeding per rectum, that are initially attributed to benign causes such as hemorrhoids, which may co-exist. On the other hand, young adults are more likely to have competing responsibilities and may be less likely to seek professional help early, as they may normalize or wrongly attribute their symptoms to something other than cancer, thereby further adding to potential diagnostic delay [27]. Globally, established CRC screening programs in their current shape include patients $>50$ years old and although there is no data to confirm this, it is possible that this may contribute to the fact that young patients tend to present with more advanced stage at diagnosis. Our data adds further 
evidence supporting recent publications that suggest that CRC screening should be more inclusive of younger patients [28]. Indeed, the American cancer society has recently recommended lowering the age to start CRC screening from 50 to 45 years with either a high-sensitivity stool-based test or a structural (visual) examination, depending on patient preference and test availability [29].

In our cohort a minority of patients had a known hereditary syndrome $(7 \%)$, with the most prevalent syndrome being, as expected, Lynch syndrome. Overall the rate of known hereditary syndromes in our cohort is at the lower end of the spectrum when compared to previously reported studies $[12,13]$. This may have been due to the fact that other retrospective studies in EOCRC included a younger group by only including patients aged $<40$ years old. It is well established that the younger the median age of the EOCRC cohort, the higher the rate of hereditary etiology $[12,19]$. Patients with known hereditary syndromes remain an important proportion of the EOCRC population that require specialist cancer genetics input and specialized surveillance strategies. Nevertheless, it is also important to acknowledge that the majority of young adults with CRC are in fact patients with nonhereditary sporadic tumors.

Our molecular characterization results for MMR status as well as KRAS/NRAS and BRAF mutation rates reflect the fact that during the earlier years of data collection, molecular characterization was not routinely carried out, which is currently not the case. Our data is in line with the existing literature on rates of KRAS mutations in the general CRC population and also with that reported in other retrospective EOCRC series [30,31]. Our MMR deficiency rates are consistent with that reported by other studies that also suggested that MSI tumors are more common in EOCRC [15,31]. In line with the general CRC population, our EOCRC patients with MMR deficient tumors had an earlier stage at diagnosis when compared to patients with MMR proficient tumors. Only one in 17 (6\%) patients with MMR deficient CRC presented with metastatic disease, as compared to our overall $39 \%$ rate of metastatic CRC at diagnosis. This is of clinical relevance, as patients with MMR deficient tumors are likely to respond to immune checkpoint inhibitors [32].

Importantly, to date, there are no prospective trials that were designed to explicitly investigate the efficacy of SACT in young CRC adults. As a consequence of this, the treatment of these patients is largely based on extrapolating results from clinical trials that enrolled older patients. We therefore sought to analyze the treatment patterns and outcomes of patients with EOCRC, who were treated within our UK specialist cancer center, as this would serve as a baseline for future prospective research.

In our patients with stage II disease, a higher than expected proportion $(60 \%)$ went on to receive adjuvant chemotherapy. Clinical trials in age-unselected populations suggested that the absolute survival benefit of adjuvant chemotherapy in stage II CRC is in the order of $4 \%$ [33]. We speculate that the high uptake of adjuvant chemotherapy in our stage II EOCRC patients probably reflects the fact that younger patients are willing to have any treatment with possible benefit, even if the likelihood of benefit is low. Overall, the RFS rates for both stage II and III patients are comparable to that of historical clinical trial controls that enrolled all age groups [34]. It remains unknown as to whether intensification of adjuvant chemotherapy in EOCRC is of any benefit. Other retrospective trials also suggest that adults with EOCRC receive significantly more postoperative SACT at all stages, but they experience only minimal gain in adjusted survival compared with their older counterparts who receive less treatment $[21,35]$. A circulating tumor DNA (ctDNA)-based risk stratification strategy may permit for the better selection of patients that are likely to benefit from adjuvant chemotherapy and prospective trials investigating this are currently underway [36].

To our knowledge we are the first to profile the regimens used and outcomes per line of palliative SACT in young adults with mCRC. In the first line setting, $99 \%$ of our patients had doublet chemotherapy, with the addition of targeted therapy in more than half of the patients. The majority of patients went on to have standard of care second line SACT with a third of all metastatic patients having at least three lines of therapy. From the third line SACT setting onwards, $20 \%$ of patients had their treatment within clinical trials, while the remaining patients often had a rechallenge of previously used regimens. Many patients had other additional palliative treatments such as surgery, radiotherapy, and 
localized treatments such as RFA to the liver and/or lung metastases. These results are overall reflective of a fit and motivated cohort of patients, who were treated with all evidence-based multimodality therapies. Whilst noting the limitations associated with a single center (albeit a high-volume cancer specialist hospital) our data suggests that there may be scope for prospective clinical trials tailored specifically for young adults with CRC.

The partial response rate and median PFS rates in the first- and second-line metastatic setting compare unfavorably to published data in unselected patients in terms of age, including data from other real-world observational trials [30,37-39]. In our study, young patients that were able to have sequential SACT for metastatic disease had a numerically higher mOS, with a stepwise improvement in their mOS with increasing lines of SACT. It is however worth noting that during the data collection period included (January 2009-December 2014), first line triplet cytotoxic chemotherapy combination with FOLFOXIRI (a combination of 5FU, oxaliplatin, and Irinotecan) and bevacizumab was not considered a standard of care option, and therefore it was not one of the used regimens in our study [40]. Since 2014, there has been data in support of this regimen and we expect that it is now more commonly used in fit young adults with metastatic CRC, especially where a conversion approach is possible or in patients with known right sided or BRAF mutant primary tumors [41,42].

In the current literature there is scarcity of studies that reported the response to specific SACT. We could not identify any other trials that reported PFS and response rates (RR) per line of SACT in young patients with mCRC. An older trial, with a pooled analysis of patients from nine first line phase III chemotherapy trials using fluorouracil-based single-agent and combination chemotherapy, suggested that young age is modestly associated with poorer PFS but not OS or RR in treated patients with advanced CRC [43]. The only other trial that reported PFS rates in the first line SACT setting for young adults with $\mathrm{mCRC}$ by retrospectively assessing the effect of age on outcomes from 24 first line clinical trials, reported that younger and older age are associated with poorer OS and PFS when compared to middle-aged patients [44].

In our study, the mOS of 20.1 months (95\% C.I: 15.9-23.2) for all patients with mEOCRC was lower than expected, particularly given the fact that these patients were otherwise of a good PS and were treated with what were at the time considered the most efficacious multimodality therapies available. One of the most notable findings of our study was the fact that younger age at diagnosis was in fact associated with a shorter mOS with an inverse relationship between age and mOS.

We identified signet cell histological subtype which was present in $5 \%$ of patients, as a poor prognostic marker for OS in mEOCRC. However, given the small number of patients with signet cell histology, this cannot explain the overall short mOS of this cohort or the shorter mOS amongst the youngest included patients. Previous retrospective studies compared the prognosis of patients with EOCRC to that of older counterparts. A recent review of these trials reported mixed results, with some studies indicating a poorer prognosis, whereas others support a comparable or even better prognosis in comparison with older patients [35]. In line with our results, there have been previous reports suggesting that the younger end of the EOCRC spectrum have inferior survival outcomes [31,44].

In the current literature there is preliminary evidence to suggest that the pathological and molecular characteristics of the tumors of young patients with EOCRC differ from that of older patients. In line with our results, signet cell histology is over-represented in young patients $[9,11]$. It is likely that the EOCRC is a heterogeneous cohort in terms of disease biology, with the youngest patients being likely to have the most aggressive disease phenotype, as also suggested by our results. While EOCRC can develop through MSI or chromosomal instability (CIN) pathways, most EOCRC exhibits MSS phenotypes. Genome-wide hypomethylation is a feature of a subgroup of EOCRC. In particular, a subset of EOCRC has hypomethylation of LINE-1 sequences compared to later onset CRC. LINE-1 hypomethylation has been associated with adverse clinical behaviors. Other groups have also reported an excess of tumors that are both MSS without CIN, also known as Microsatellite and Chromosome Stable (MACS) tumors, which tend to be over-represented in poor prognosis left sided EOCRC tumors [19,45]. A recent study that investigated the molecular characteristics, including 
classification as per the transcriptomic consensus molecular subtyping (CMS), also suggested that EOCRC is a heterogeneous cohort with distinct molecular characteristics. The youngest patients, age $<30$, had distinct signaling aberrations with a lower rate of MAPK pathway mutations and a higher rate of CTNNB1 mutations. In patients younger than 40 years, CMS1 was the most common subtype, partly reflecting the higher rates of MSI. CMS3 and CMS4 were uncommon, whereas CMS2 was relatively stable across age groups [46]. Further research aiming to identify distinct molecular phenotypes of EOCRC is required as this may allow for future novel therapeutic interventions.

In addition to their differing needs in terms of anticancer therapies, it is also important to acknowledge that young patients with CRC are likely to be faced with other psychosocial concerns that are distinctly different to that of older patients. For example, these patients are likely to have concerns relating to the possible hereditary component of their disease as well as family planning and fertility preservation concerns, which should be addressed proactively during treatment planning. Other considerations include the impact of surgery, such as living with a stoma, as well as the impact of long-term side-effects of chemotherapy (such as oxaliplatin induced neuropathy) and late effect of radiotherapy on their professional and personal lives. Lastly, the psychosocial impact of having cancer at a young age in patients that were previously fit, who may have young families of their own should not be underestimated and the management of this should be incorporated into their routine clinical care. CRC services have traditionally been shaped on the assumption that CRC is a disease of older adults. We believe that both clinical services and research should adapt to take into account the needs of younger patients with CRC.

\section{Materials and Methods}

In this real-world observational study, we included patients with a histologically confirmed diagnosis of CRC between 1 January, 2009 to 31 December, 2014 that were age <50 (range 19-49) at the time of diagnosis. Patients were identified through the use of hospital diagnostic coding. All included patients received systemic anticancer therapy (SACT) at the Royal Marsden Hospital (RMH). Patients that had treatments other than SACT, such as surgery and radiotherapy at other institutions were also included, as long as this information was available for extraction from their electronic patient records.

Data were collected by review of the electronic patient medical records. The demographic data, treatment, response, and survival outcomes were recorded. Radiologic responses were recorded for each treatment line at the first response assessment point, on completion of treatment, and at any subsequent progression assessment point.

All statistical analyses were performed using the STATA 13 software package. The Kaplan-Meier method was used to estimate PFS and OS and the log-rank test was used to compare survival of patient subgroups. A $p$-value $<0.05$ was considered to be statistically significant.

This study did not require patient consent to participate. A study protocol outlining the rationale, methods, and statistical analysis plan was approved by an internal institutional review board, the Royal Marsden Hospital's Committee for Clinical Research, reference number SE474, prior to commencement and is available on request.

\section{Conclusions}

Patients with EOCRC that were treated in a single high-volume UK tertiary center had predominantly left sided, non-hereditary, primaries with advanced stage at diagnosis. Despite treatment with optimal standard of care multimodality therapies, patients with metastatic EOCRC have poorer outcomes than expected. There was an inverse relationship between age and treatment outcomes with patients at the younger end of the metastatic EOCRC spectrum exhibiting inferior mOS.

There is data to suggest that EOCRC is increasing rapidly at a global level. EOCRC is likely to be a molecularly heterogeneous disease that is distinct to that of older patients. New treatment paradigms tailored to target specific EOCRC molecular phenotypes are needed. At the same time clinical services should adapt to take the unique psychosocial needs of patients with EOCRC into account. 
Author Contributions: Conceptualization, A.G., D.C., I.C. and N.S.; methodology, A.G., S.K., E.K., K.K. data collection: A.G., S.K., A.M., N.N., V.C. and M.I.; data analysis, K.K. and A.G.; writing-original draft preparation, A.G. and P.E.; writing-review and editing, A.G., S.K., O.H., D.W., S.R., I.C. and N.S.; supervision, N.S.

Funding: This research received no external funding.

Acknowledgments: This work is supported by the National Institute for Health Research (NIHR) Biomedical Research Centre (BRC) at The Royal Marsden NHS Foundation Trust and the Institute of Cancer Research.

Conflicts of Interest: A.G., S.K., P.E., A.M., K.K., E.K., N.N., V.C., M.I., O.H., S.R. declare no conflicts of interest. D.W. received financial support from Amgen to attend a conference. IC has received advisory board fees from AstraZeneca, Bayer, Bristol-Myers Squibb, Eli-Lilly, Five Prime Therapeutics, Merck Serono, MSD, and Roche; received research funding from Eli-Lilly, Janssen-Cilag, Merck Serono, and Sanofi Oncology; and honoraria from Eli-Lilly outside the submitted work. DC has received grants from 4SC, Amgen, AstraZeneca, Bayer, Celgene, Clovis, Eli Lilly, Janssen, Medimmune, Merck, Merrimack and Sanofi outside the submitted work. NS has received research funding from AstraZeneca, Bristol-Myers Squibb, Merck Serono and honoraria from AstraZeneca.

\section{References}

1. Ferlay, J.; Soerjomataram, I.; Dikshit, R.; Eser, S.; Mathers, C.; Rebelo, M.; Parkin, D.M.; Forman, D.; Bray, F. Cancer incidence and mortality worldwide: Sources, methods and major patterns in GLOBOCAN 2012. Int. J. Cancer 2015, 136, 359-386. [CrossRef] [PubMed]

2. Pignone, M.; Rich, M.; Teutsch, S.M.; Berg, A.O.; Lohr, K.N. Screening for colorectal cancer in adults at average risk: A summary of the evidence for the U.S. Preventive Services Task Force. Ann. Intern. Med. 2002, 137, 132-141. [CrossRef] [PubMed]

3. Vuik, F.E.; Nieuwenburg, S.A.; Bardou, M.; Lansdorp-Vogelaar, I.; Dinis-Ribeiro, M.; Bento, M.J.; Zadnik, V.; Pellise, M.; Esteban, L.; Kaminski, M.F.; et al. Increasing incidence of colorectal cancer in young adults in Europe over the last 25 years. Gut 2019. [CrossRef] [PubMed]

4. Troeung, L.; Sodhi-Berry, N.; Martini, A.; Malacova, E.; Ee, H.; O’Leary, P.; Lansdorp-Vogelaar, I.; Preen, D.B. Increasing Incidence of Colorectal Cancer in Adolescents and Young Adults Aged 15-39 Years in Western Australia 1982-2007: Examination of Colonoscopy History. Front. Public Health 2017, 5, 179. [CrossRef] [PubMed]

5. $\quad$ Lui, R.N.; Tsoi, K.K.; Ho, J.M.; Lo, C.M.; Chan, F.C.; Kyaw, M.H.; Sung, J.J. Global Increasing Incidence of Young-Onset Colorectal Cancer Across 5 Continents: A Joinpoint Regression Analysis of 1,922,167 Cases. Cancer Epidemiol. Biomark. Prev. 2019. [CrossRef] [PubMed]

6. Barreto, S.G.; Chaubal, G.N.; Talole, S.; DeSouza, A.; Suradkar, K.; Gaikwad, V.; Goel, M.; Shrikhande, S.V. Rectal cancer in young Indians-Are these cancers different compared to their older counterparts? Indian J. Gastroenterol. 2014, 33, 146-150. [CrossRef]

7. Siegel, R.L.; Fedewa, S.A.; Anderson, W.F.; Miller, K.D.; Ma, J.; Rosenberg, P.S.; Jemal, A. Colorectal Cancer Incidence Patterns in the United States, 1974-2013. J. Natl. Cancer Inst. 2017, 109. [CrossRef]

8. Ahnen, D.J.; Wade, S.W.; Jones, W.F.; Sifri, R.; Mendoza Silveiras, J.; Greenamyer, J.; Guiffre, S.; Axilbund, J.; Spiegel, A.; You, Y.N. The increasing incidence of young-onset colorectal cancer: A call to action. Mayo Clin. Proc. 2014, 89, 216-224. [CrossRef]

9. Silla, I.O.; Rueda, D.; Rodriguez, Y.; Garcia, J.L.; De la Cruz Vigo, F.; Perea, J. Early-onset colorectal cancer: A separate subset of colorectal cancer. World J. Gastroenterol. 2014, 20, 17288-17296. [CrossRef]

10. Perea, J.; Rueda, D.; Canal, A.; Rodriguez, Y.; Alvaro, E.; Osorio, I.; Alegre, C.; Rivera, B.; Martinez, J.; Benitez, J.; et al. Age at onset should be a major criterion for subclassification of colorectal cancer. J. Mol. Diagn. 2014, 16, 116-126. [CrossRef]

11. Connell, L.C.; Mota, J.M.; Braghiroli, M.I.; Hoff, P.M. The Rising Incidence of Younger Patients With Colorectal Cancer: Questions About Screening, Biology, and Treatment. Curr. Treat. Options Oncol. 2017, 18, 23. [CrossRef] [PubMed]

12. Mork, M.E.; You, Y.N.; Ying, J.; Bannon, S.A.; Lynch, P.M.; Rodriguez-Bigas, M.A.; Vilar, E. High Prevalence of Hereditary Cancer Syndromes in Adolescents and Young Adults With Colorectal Cancer. J. Clin. Oncol. 2015, 33, 3544-3549. [CrossRef] [PubMed]

13. Stigliano, V.; Sanchez-Mete, L.; Martayan, A.; Anti, M. Early-onset colorectal cancer: A sporadic or inherited disease? World J. Gastroenterol. 2014, 20, 12420-12430. [CrossRef] [PubMed]

14. Lynch, H.T.; De la Chapelle, A. Hereditary colorectal cancer. N. Engl. J. Med. 2003, 348, 919-932. [CrossRef] 
15. Yiu, R.; Qiu, H.; Lee, S.H.; Garcia-Aguilar, J. Mechanisms of microsatellite instability in colorectal cancer patients in different age groups. Dis. Colon Rectum 2005, 48, 2061-2069. [CrossRef]

16. Bailey, C.E.; Hu, C.Y.; You, Y.N.; Bednarski, B.K.; Rodriguez-Bigas, M.A.; Skibber, J.M.; Cantor, S.B.; Chang, G.J. Increasing disparities in the age-related incidences of colon and rectal cancers in the United States, 1975-2010. JAMA Surg. 2015, 150, 17-22. [CrossRef]

17. Siegel, R.L.; Medhanie, G.A.; Fedewa, S.A.; Jemal, A. State variation in early-onset colorectal cancer in the United States, 1995-2015. J. Natl. Cancer Inst. 2019. [CrossRef]

18. Carroll, R.; Zhao, S. Trends in Colorectal Cancer Incidence and Survival in Iowa SEER Data: The Timing of It All. Clin. Colorectal Cancer 2018. [CrossRef]

19. Dwyer, A.J.; Murphy, C.C.; Boland, C.R.; Garcia, R.; Hampel, H.; Limburg, P.; Lowery, J.; Zauber, A.G.; Waring, S.; Worrall, S.; et al. A summary of the Fight Colorectal Cancer working meeting: Exploring risk factors and etiology of sporadic early-age onset colorectal cancer. Gastroenterology 2019. [CrossRef]

20. Meyer, J.E.; Narang, T.; Schnoll-Sussman, F.H.; Pochapin, M.B.; Christos, P.J.; Sherr, D.L. Increasing incidence of rectal cancer in patients aged younger than 40 years: An analysis of the surveillance, epidemiology, and end results database. Cancer 2010, 116, 4354-4359. [CrossRef]

21. Kneuertz, P.J.; Chang, G.J.; Hu, C.Y.; Rodriguez-Bigas, M.A.; Eng, C.; Vilar, E.; Skibber, J.M.; Feig, B.W.; Cormier, J.N.; You, Y.N. Overtreatment of young adults with colon cancer: More intense treatments with unmatched survival gains. JAMA Surg. 2015, 150, 402-409. [CrossRef] [PubMed]

22. Alvaro, E.; Cano, J.M.; Garcia, J.L.; Brandariz, L.; Olmedillas-Lopez, S.; Arriba, M.; Rueda, D.; Rodriguez, Y.; Canete, A.; Arribas, J.; et al. Clinical and Molecular Comparative Study of Colorectal Cancer Based on Age-of-onset and Tumor Location: Two Main Criteria for Subclassifying Colorectal Cancer. Int. J. Mol. Sci. 2019, 20, 968. [CrossRef] [PubMed]

23. Russo, A.G.; Andreano, A.; Sartore-Bianchi, A.; Mauri, G.; Decarli, A.; Siena, S. Increased incidence of colon cancer among individuals younger than 50 years: A 17 years analysis from the cancer registry of the municipality of Milan, Italy. Cancer Epidemiol. 2019, 60, 134-140. [CrossRef] [PubMed]

24. Segev, L.; Kalady, M.F.; Church, J.M. Left-Sided Dominance of Early-Onset Colorectal Cancers: A Rationale for Screening Flexible Sigmoidoscopy in the Young. Dis. Colon Rectum 2018, 61, 897-902. [CrossRef] [PubMed]

25. Ben-Ishay, O.; Brauner, E.; Peled, Z.; Othman, A.; Person, B.; Kluger, Y. Diagnosis of colon cancer differs in younger versus older patients despite similar complaints. Isr. Med. Assoc. J. 2013, 15, 284-287.

26. Olivo, R.; Ratnayake, S. Colorectal cancer in young patients: A retrospective cohort study in a single institution. ANZ J. Surg. 2019. [CrossRef]

27. Gibson, F.; Pearce, S.; Fern, L.; Martins, A.; Kelly, D. Improving the identification of cancer in young people: A scoping review. Expert Rev. Qual. Life Cancer Care 2017, 2, 87-101. [CrossRef]

28. Kasi, P.M.; Shahjehan, F.; Cochuyt, J.J.; Li, Z.; Colibaseanu, D.T.; Merchea, A. Rising Proportion of Young Individuals With Rectal and Colon Cancer. Clin. Colorectal Cancer 2018. [CrossRef]

29. Wolf, A.M.D.; Fontham, E.T.H.; Church, T.R.; Flowers, C.R.; Guerra, C.E.; LaMonte, S.J.; Etzioni, R.; McKenna, M.T.; Oeffinger, K.C.; Shih, Y.T.; et al. Colorectal cancer screening for average-risk adults: 2018 guideline update from the American Cancer Society. CA A Cancer J. Clin. 2018, 68, 250-281. [CrossRef]

30. Cunningham, D.; Atkin, W.; Lenz, H.J.; Lynch, H.T.; Minsky, B.; Nordlinger, B.; Starling, N. Colorectal cancer. Lancet (London, England) 2010, 375, 1030-1047. [CrossRef]

31. Khan, S.A.; Morris, M.; Idrees, K.; Gimbel, M.I.; Rosenberg, S.; Zeng, Z.; Li, F.; Gan, G.; Shia, J.; LaQuaglia, M.P.; et al. Colorectal cancer in the very young: A comparative study of tumor markers, pathology and survival in early onset and adult onset patients. J. Pediatr. Surg. 2016, 51, 1812-1817. [CrossRef] [PubMed]

32. Le, D.T.; Durham, J.N.; Smith, K.N.; Wang, H.; Bartlett, B.R.; Aulakh, L.K.; Lu, S.; Kemberling, H.; Wilt, C.; Luber, B.S.; et al. Mismatch repair deficiency predicts response of solid tumors to PD-1 blockade. Science (New York, NY) 2017, 357, 409-413. [CrossRef] [PubMed]

33. Gray, R.; Barnwell, J.; McConkey, C.; Hills, R.K.; Williams, N.S.; Kerr, D.J. Adjuvant chemotherapy versus observation in patients with colorectal cancer: A randomised study. Lancet (London, England) 2007, 370, 2020-2029. [CrossRef]

34. Iveson, T.J.; Kerr, R.S.; Saunders, M.P.; Cassidy, J.; Hollander, N.H.; Tabernero, J.; Haydon, A.; Glimelius, B.; Harkin, A.; Allan, K.; et al. 3 versus 6 months of adjuvant oxaliplatin-fluoropyrimidine combination therapy 
for colorectal cancer (SCOT): An international, randomised, phase 3, non-inferiority trial. Lancet Oncol. 2018, 19, 562-578. [CrossRef]

35. Mauri, G.; Sartore-Bianchi, A.; Russo, A.G.; Marsoni, S.; Bardelli, A.; Siena, S. Early-onset colorectal cancer in young individuals. Mol. Oncol. 2019, 13, 109-131. [CrossRef]

36. Khakoo, S.; Georgiou, A.; Gerlinger, M.; Cunningham, D.; Starling, N. Circulating tumour DNA, a promising biomarker for the management of colorectal cancer. Crit. Rev. Oncol. Hematol. 2018, 122, 72-82. [CrossRef]

37. Van Cutsem, E.; Rivera, F.; Berry, S.; Kretzschmar, A.; Michael, M.; DiBartolomeo, M.; Mazier, M.A.; Canon, J.L.; Georgoulias, V.; Peeters, M.; et al. Safety and efficacy of first-line bevacizumab with FOLFOX, XELOX, FOLFIRI and fluoropyrimidines in metastatic colorectal cancer: The BEAT study. Ann. Oncol. 2009, 20, 1842-1847. [CrossRef]

38. Kozloff, M.; Yood, M.U.; Berlin, J.; Flynn, P.J.; Kabbinavar, F.F.; Purdie, D.M.; Ashby, M.A.; Dong, W.; Sugrue, M.M.; Grothey, A. Clinical outcomes associated with bevacizumab-containing treatment of metastatic colorectal cancer: The BRiTE observational cohort study. Oncologist 2009, 14, 862-870. [CrossRef]

39. Khakoo, S.; Chau, I.; Pedley, I.; Ellis, R.; Steward, W.; Harrison, M.; Baijal, S.; Tahir, S.; Ross, P.; Raouf, S.; et al. ACORN: Observational Study of Bevacizumab in Combination With First-Line Chemotherapy for Treatment of Metastatic Colorectal Cancer in the UK. Clin. Colorectal Cancer 2019. [CrossRef]

40. Cremolini, C.; Loupakis, F.; Antoniotti, C.; Lupi, C.; Sensi, E.; Lonardi, S.; Mezi, S.; Tomasello, G.; Ronzoni, M.; Zaniboni, A.; et al. FOLFOXIRI plus bevacizumab versus FOLFIRI plus bevacizumab as first-line treatment of patients with metastatic colorectal cancer: Updated overall survival and molecular subgroup analyses of the open-label, phase 3 TRIBE study. Lancet Oncol. 2015, 16, 1306-1315. [CrossRef]

41. Loupakis, F.; Cremolini, C.; Salvatore, L.; Masi, G.; Sensi, E.; Schirripa, M.; Michelucci, A.; Pfanner, E.; Brunetti, I.; Lupi, C.; et al. FOLFOXIRI plus bevacizumab as first-line treatment in BRAF mutant metastatic colorectal cancer. Eur. J. Cancer 2014, 50, 57-63. [CrossRef] [PubMed]

42. Cremolini, C.; Antoniotti, C.; Lonardi, S.; Bergamo, F.; Cortesi, E.; Tomasello, G.; Moretto, R.; Ronzoni, M.; Racca, P.; Loupakis, F.; et al. Primary tumor sidedness and benefit from FOLFOXIRI plus bevacizumab as initial therapy for metastatic colorectal cancer. Retrospective analysis of the TRIBE trial by GONO. Ann. Oncol. 2018. [CrossRef] [PubMed]

43. Blanke, C.D.; Bot, B.M.; Thomas, D.M.; Bleyer, A.; Kohne, C.H.; Seymour, M.T.; de Gramont, A.; Goldberg, R.M.; Sargent, D.J. Impact of young age on treatment efficacy and safety in advanced colorectal cancer: A pooled analysis of patients from nine first-line phase III chemotherapy trials. J. Clin. Oncol. 2011, 29, 2781-2786. [CrossRef] [PubMed]

44. Lieu, C.H.; Renfro, L.A.; De Gramont, A.; Meyers, J.P.; Maughan, T.S.; Seymour, M.T.; Saltz, L.; Goldberg, R.M.; Sargent, D.J.; Eckhardt, S.G.; et al. Association of age with survival in patients with metastatic colorectal cancer: Analysis from the ARCAD Clinical Trials Program. J. Clin. Oncol 2014, 32, 2975-2984. [CrossRef] [PubMed]

45. Cavestro, G.M.; Mannucci, A.; Zuppardo, R.A.; Di Leo, M.; Stoffel, E.; Tonon, G. Early onset sporadic colorectal cancer: Worrisome trends and oncogenic features. Dig. Liver Dis. 2018, 50, 521-532. [CrossRef]

46. Willauer, A.N.; Liu, Y.; Pereira, A.A.L.; Lam, M.; Morris, J.S.; Raghav, K.P.S.; Morris, V.K.; Menter, D.; Broaddus, R.; Meric-Bernstam, F.; et al. Clinical and molecular characterization of early-onset colorectal cancer. Cancer 2019, 125, 2002-2010. [CrossRef]

(C) 2019 by the authors. Licensee MDPI, Basel, Switzerland. This article is an open access article distributed under the terms and conditions of the Creative Commons Attribution (CC BY) license (http://creativecommons.org/licenses/by/4.0/). 